\title{
LITERATURA, CIBERLITERATURA E A FORMAÇÃO DE ALUNOS-LEITORES: DIÁlOGOS COM O CÂNONE E A FICÇÃO DE FÃS
}

Ana Cláudia Silva Fidelis Eliane Fernandes Azzari

\begin{abstract}
RESUMO
Ressignificados pelo desenvolvimento das tecnologias síncronas, os textos contemporâneos privilegiam a colaboração e a interatividade entre autores e leitores, reconfigurando seus papéis. Neste artigo, revisitamos o lugar da leitura e a posição do leitor, problematizando o lugar que ocupam o cânone e o fânone (neologismo para o conjunto de textos de fẫs) nos letramentos escolares na atualidade.
\end{abstract}

PALAVRAS-CHAVE: letramentos; literatura; tecnologias digitais.

\section{Introdução}

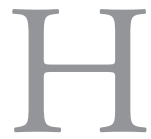

oje, muito se discute sobre o desinteresse do jovem em relação ao universo letrado, em particular à leitura dos clássicos ou dos livros que compóem o cânone literário. De um lado, pode-se perceber um movimento de valorização de uma tradição literária e de seus principais representantes (sejam autores ou obras mais significativas) e, de outro, uma ampla negação desse mesmo cânone, por parte daqueles que deveriam, em tese, ser seu público. O resultado, portanto, é um descompasso entre as escolhas feitas pelas instituições responsáveis por determinado cânone e as escolhas do público.

Caminhando paralelamente ao quadro descrito, para além dos muros da escola e da academia, encontram-se produçóes textuais amplamente lidas, 
comentadas e compartilhadas, especialmente circuladas no universo das culturas da juventude, aproximadas pela afiliação ${ }^{1}$ a uma base de fãs.

A cultura de fá, apoiada nas tecnologias digitais, tem promovido, entre outros aspectos, um verdadeiro boom na produção de gêneros diversos, novos e/ou revisitados. A prática da escrita criativa, na roupagem da fanfic (forma abreviada do inglês para fanfiction, que representa a ficção ou história de fầs), é um deles, talvez uma tentativa de reencarnar antigas práticas escritas como os folhetins e fanzines - termo cunhado do inglês fan magazines ou revistas de fấs (VIIRES, 2005, p. 153). Nesse contexto, milhares de estórias de fã̃s são escritas, publicadas e lidas em ambiente digital e globalmente divulgadas e acessadas, de modo veloz. Nas tramas hipermidiáticas da web $2.0^{2}$, nascem novos autores e leitores diariamente. Essas produçóes textuais não são mais estanques, ao contrário, são mutáveis, fruto de colaborações, releituras, que podem ser de cânone ${ }^{3}$ ou de outros textos diversos ${ }^{4}$, orientadas pelo desejo de expressar o pertencimento, de participar, de ouvir e ser ouvido.

E enquanto o engajamento de jovens alunos em práticas de escrita e leitura, em esfera escolar, constitui um colossal desafio para o professor de línguas e literaturas, a escrita criativa, por meio da narrativa ficcional hipermediática, brota aos milhares nas páginas de plataformas como a $<$ fanfiction.net $>$

1 Afiliação, neste contexto, é compreendida como "associação, formal ou informal, a comunidades síncronas situadas em diferentes formas de mídia” (JENKINS et al, 2006, p.03, tradução nossa).

2 WWW é a sigla para World Wide Web, um aplicativo surgido na década de 1990. O termo em inglês indica a rede mundial de informaçóes, uma forma de acesso possibilitada pela internet, que é a infraestrutura maior que interconecta computadores de todo o mundo. A segunda fase da web, a web 2.0, surgiu no início dos anos 2000. O termo web 2.0 foi cunhado por O'Reilly em 2005; segundo ele, a grande virada ocorreu na passagem de sítios mais estáticos da web 1.0 para outros mais colaborativos e participativos, característicos da segunda fase da rede. Para maior detalhamento, veja: O'REILLY, T. What Is Web 2.0? Design Patterns and Business Models for the Next Generation of Software, disponível em: http://www.oreilly.com/pub/a/web2/archive/what-is-web-20.html. Acesso em 18 jan 2016.

3 Veja-se como exemplo fanfics criadas a partir da obra Orgulho e Preconceito, da escritora inglesa Jane Austen, escritas em diversas línguas, inclusive o português, como a estória disponível em: https://www.fanfiction.net/s/3674150/1/Orgulho-e-Preconceito. Acesso em $29 / 10 / 2015$.

4 Há fanfics desenvolvidas a partir de diversos motivadores, tais como: seriados de televisão; filmes; grupos musicais; quadrinhos e, ainda, atores e cantores. Os motivadores para os textos são, em resumo, aspectos da cultura do fã a partir dos quais são feitas reelaborações. 
(sobre a qual comentaremos mais adiante neste texto). Nesse sítio, há fanfics publicadas com mais de cem capítulos e algumas histórias totalizam $500 \mathrm{mil}$ palavras. Veja o exemplo de um desses textos na figura $1^{5}$, que apresenta um recorte da página de uma dentre milhares de histórias de fấs escritas a partir da saga Crepúsculo, de Stephenie Meyer.

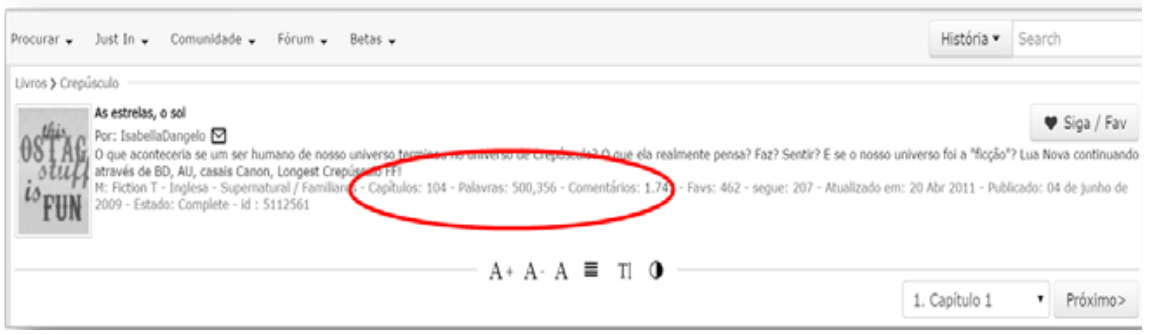

Figura 1 - Recorte da página de uma fanfic com mais de 100 capítulos e 500 mil palavras, publicada no site $<$ fanfiction.net.> (destaque nosso). Disponível em: https://www.fanfiction.net/s/5112561/1/The-stars-and-the-sun. Acesso em 19 jan 2016.

A partir do exposto, revisitamos neste artigo os conceitos de literatura e ciberliteratura - o cânone e as ficções de fấs -, problematizando suas interfaces com o papel do leitor contemporâneo, direcionando nosso olhar para os desafios diante da formação de um aluno-leitor em uma sociedade globalizada e permeada pelas ressignificaçóes fomentadas pelas tecnologias e ambientes digitais.

\section{Literatura, cânone literário e a legitimação de textos na escola}

Se considerarmos que a literatura é um dos principais organizadores da cultura humana (um modelo de comunicação) e um polissistema, ou seja, um sistema múltiplo, com estrutura dinâmica e heterogênea que se configura por uma série de sobreposiçóes e intersecçóes, não se pode inferir que a literatura seja sinônimo de cânone ou a ele se restrinja. Ademais, é preciso compreender que a literatura em sua face mais concreta - os textos - passa por um processo de canonização que se relaciona às leis e normas de funcionamento estabelecidas

5 A página em destaque está originalmente publicada em língua inglesa, mas foi traduzida para o português via ferramenta disponível no aplicativo/navegador Google Chrome a fim de ilustrar a discussão aqui apresentada. 
no interior do sistema por seus elementos constitutivos, entre eles: produtores, consumidores, produtos, repertório, as instituiçóes e o mercado (EVEN-ZOHAR, 1990).

O processo de canonização relaciona-se, portanto, a ao menos três fatores interdependentes: a produção dos textos literários, com certas propriedades que se tornam canonizadas; ao papel da crítica; e o papel do público. A canonicidade de um texto, portanto, não é uma característica intrínseca, mas dá-se por um processo em que algumas leis podem ser consideradas universais e outras estáo sujeitas a diferentes períodos e culturas e ao maior prestígio de algumas das instâncias legitimadoras em relação a outras.

Os textos, portanto, transmutam-se em uma literatura canonizada, e esta, por sua vez, torna-se sinônimo de cultural oficial - o centro do sistema-, e o repertório de maior prestígio. Este repertório cultural passa a ser o conjunto de modelos (normas e obras) que devem ser preservados pela comunidade como herança cultural. Isto não significa, de forma alguma, que os demais sistemas, aqui denominados periféricos, não estejam vivos e não interfiram, inclusive, para mudanças estruturais em seu centro.

Considerando os três fatores citados acima, cabe à crítica ${ }^{6}$ o papel de formador de opiniáo, na medida em que reflete sobre o objeto literário, sobre sua constituição e, principalmente, sobre os critérios de legitimação das obras. Assim, diante do inevitável que é a obra, o crítico elabora um discurso fundador do campo de conhecimento e é esse discurso que traz as bases do que se compreende por literatura, por valor literário, por obra de arte e que impóe, portanto, as regras, as medidas reguladoras do território literário, marcando as fronteiras do que é e do que não é considerado literatura e, dentro desse conjunto, o que é a literatura canonizada e a literatura náo canonizada.

O discurso fundador define, assim, o conjunto de obras e escritores capazes de representar $A$ literatura. Nesse sentido, esse discurso traça e demarca o território literário, define e defende suas fronteiras, controla as entradas e saídas dos objetos literários e é responsável pela defesa da ordem estabelecida.

6 Pela própria etimologia da palavra, crítica implica julgamento (krinein = julgar). Desde sua prática autoritária no século XVII, sob a forma de decretos da Academia, passando pelas escolhas já pessoais dos críticos do século XVIII, até o fim do século XIX, quando ela atingiu a plenitude de seus meios e de seu poder como instituição autônoma, a crítica literária reivindicou e exerceu a função de julgar. Cf. PERRONE-MOISÉS, Leyla. Altas literaturas: escolha e valor na obra crítica de escritores modernos. São Paulo: Companhia das letras. 1998, p. 09. 
No entanto, esse discurso não é uno, único e permanente. Ele se compõe, se decompóe, se transforma, se organiza num movimento contínuo, no próprio processo constitutivo do campo literário. Assim, pode-se falar de discursos fundadores que lutam entre si pela primazia de poder sobre as regras que estabelecem os limites do território literário. É sobre esses discursos fundantes que recai o principal critério de valor quando se trata do objeto literário, o que significa afirmar que mais importante torna-se uma obra literária em sua tradição quanto maior for seu reconhecimento (ou seu grau de consagração) pela crítica e pelos escritores do que por seu reconhecimento perante o grande público (BOURDIEU, 1996). Por esse critério, a legitimação de uma obra como literária se dá de fato pelos juízos de valor expressos pela crítica, que assume, no jogo de forças, um grau de importância maior do que o público.

As possíveis diferenças entre os modos de reconhecimento por parte do público e da crítica explicam as muitas situaçóes em que as escolhas literárias da crítica especializada não correspondem às escolhas feitas pelo público. Além disso, revelam-se os sempre possíveis erros de percepção e de apreciação que podem inscrever ou não escritores no cânone, evidenciando os casos de recuperação e de nova inserção no cânone, de um lado, e, de outro, os "apagamentos" de alguns nomes que não resistem à ação do tempo. Explicita-se, ainda, a defasagem entre o sucesso temporal e o valor artístico. Em muitos casos, uma determinada obra alcança um rápido e grande sucesso entre o público que não se sustenta em relação ao valor que a crítica a ela atribui.

O valor da obra é fruto, portanto, de um pacto que se estabelece entre os agentes do território literário, responsáveis pela produção de seu valor ${ }^{7}$. Dessa forma, por meio de um acordo tácito e tenso (porque não sem luta interna), elabora-se o que é o literário e qual seu valor e, de maneira concreta, quais as obras (e escritores) representativas desse literário e personificaçóes desse valor. Trata-se do critério da autoridade. Quanto mais se diz do valor de uma obra literária, mais essa afirmação se consolida como realidade e mais se reforça novamente como discurso; é "um enunciado cuja enunciação aumenta as suas chances de verdade" (COMPAGNON, 2001, p. 254).

7 A economia literária seria, portanto, abrigada por um "mercado", isto é, um espaço onde circularia e se permutaria o único valor reconhecido por todos os participantes: o valor literário. Cf. CASANOVA, Pasquale. A república mundial das letras. São Paulo: Estação Liberdade. 2002, p. 28. 
Deter o monopólio da legitimidade é um dos motivos centrais das rivalidades literárias; isto porque, através dele, adquire-se o poder dizer quem está autorizado a dizer-se escritor ou mesmo a dizer quem é escritor e quem tem autoridade para dizer quem é escritor; ou, se preferir, o monopólio do poder de consagração dos produtores ou dos produtos (BOURDIEU, 1996, p. 253).

Cabe à crítica (e ao público), ainda, dar movimento a esse processo infindo e constante de legitimação do literário através da inclusão de novos princípios legitimadores aos já existentes ou, ainda, do resgate de princípios legitimadores antigos que foram, no decurso histórico, esquecidos ou mesmo apagados. Esta possível mobilidade dos critérios de legitimação permite que o cânone não se torne algo fechado, estático; pois redefine o direito de entrada das obras no território literário e torna suas fronteiras relativamente móveis. Apesar da possibilidade de mudanças, o que se percebe é a pouca mutabilidade dos critérios de valoração.

Desse modo, esse processo de legitimação ocorre, num primeiro momento, na tessitura do discurso da crítica e historiografia literárias que, ao longo do tempo, vão indicando as obras que compóem a representatividade de uma literatura nacional, numa construção discursiva em que o prestígio da instância de legitimação, no caso a academia, valida o próprio processo de legitimação.

Por seu turno, a construção do cânone no ambiente escolar se dá por um mecanismo em espiral que nasce da apropriação do discurso da crítica literária e passa pela legitimação desse discurso nos livros didáticos de literatura e língua (portuguesa e/ou estrangeira), enformando o discurso praticado na escola, influenciando a prática de professores e as linhas de estudo (por exemplo, para a literatura brasileira e/ou de obras primariamente escritas em línguas estrangeiras) nos diferentes segmentos de ensino, reverberando, portanto, a leitura dos chamados clássicos, a despeito dos movimentos de resistência do público-alvo (neste caso, jovens alunos).

O que se verifica, portanto, quando se trata de leitura literária no ambiente escolar e no que se refere à formação do leitor, é que cânone escolar, ou seja, as obras referendadas para leitura no ambiente escolar, embora se mostre um registro parcial, reafirma certas escolhas canônicas feitas pela crítica e pela historiografia literárias (brasileiras e/ou estrangeiras), revelando um movimento, dentro de um leque amplo de obras e autores, entre um centro canônico e sua periferia, ou seja, entre autores sempre canônicos e outros eventualmente canônicos. 
Não se pode negar que a prática pedagógica nas escolas está diretamente relacionada às escolhas feitas pelos professores responsáveis, pois as aulas de literatura e línguas (materna e/ou estrangeiras) são pensadas, estruturadas e ministradas tendo em vista os romances e autores referendados, num primeiro momento, pela crítica e pela tradição, e, posteriormente, pela escola. Portanto, essas escolhas, além de reafirmarem o caráter canônico de determinados textos e autores, delineiam a maneira como professores e alunos passam a formular suas hipóteses sobre o literário e sobre o que é literatura, bem como selecionam o que o estudante lerá em seus anos escolares, demarcando o muito ou pouco de sua formação como leitor.

Percebe-se, portanto, a força que o cânone passa a ter, em função de seu caráter organizacional de um dado número de autores e obras que se colocam para o público leitor como representação de um valor estético e literário. A sua força enformadora, delineando o que se lê em determinados momentos do percurso escolar, legitima-se, pois, graças a três aspectos complementares: o respaldo institucional, o próprio processo de escolha, capaz de legitimar-se como critério de valor, e a reafirmação do cânone literário consagrado pela crítica e historiografia literárias.

Diante desse quadro, coloca-se como desafio, atualmente, ao professor formador do aluno-leitor, a tarefa de navegar pelo cânone legitimado pela esfera escolar - e as forças, poderes e juízos de valor que o norteiam - e as demandas de uma sociedade em que textos são hibridizados, ressignificados, remixados, compartilhados e lidos de maneira (quase) instantânea.

\section{A ciberliteratura, a ficção de fãs e a leitura para além das fronteiras escolares}

A navegação online (síncrona) permitiu o desenvolvimento e o acesso a ambientes digitais pelos quais e nos quais o engajamento em (novas) práticas sociais letradas é fomentado através dos recursos oferecidos pelas TDICs ${ }^{8}$. A interatividade, uma característica "intrínseca da comunicação digital" (SANTAELLA, 2012, p. 410), apoiada na multimodalidade, hipertextualidade e colaboração - possibilitadas por aqueles recursos -, permitiu a propagação de (novos) gêneros centrados na escrita.

8 Sigla para Tecnologias Digitais da Informação e Comunicação. 
Some-se a esse quadro o fortalecimento da "cultura de fâ" que, como aponta Jenkins (1992), ao apropriar-se de um texto de outrem para si próprio, contribui para a construção de uma "cultura alternativa".

As ficçóes escritas e divulgadas por fấs podem ser classificadas, segundo Viires (2005), como uma das categorias abrigadas sob a chamada ciberliteratura. Para ele, esse gênero é um exemplo de "textos literários não profissionais, disponíveis na internet, cuja inclusão na análise literária expandiria as noções estabelecidas pelo cânone" (VIIRES, 2005, p. 154, nossa tradução).

De natureza multimodal, metalinguística e baseada na colaboração e na remixagem ${ }^{9}$, o gênero ${ }^{10}$ fanfic carrega indicações de uma nova prática social associada a novas técnicas e mentalidade, características constituintes de um novo ethos, como o conceituam Lankshear e Knobel (2008, p.08).

A figura 2 ilustra algumas dessas características, mostrando um recorte de uma página que lança um desafio / concurso para que se escrevam histórias que sejam um "crossover" - denominação que indica ao leitor-escritor que a fanfic deverá "cruzar" duas ou mais histórias / personagens / mídias, estabelecendo, dessa forma, vínculo com duas bases de fấs diferentes. No caso ilustrativo, o desafio proposto envolve cruzar as sagas Harry Potter e Naruto ${ }^{11}$. O anúncio pede que os interessados em responder ao desafio comentem a publicação (o que é possível fazer para quaisquer histórias / anúncios publicados na página, desde que os autores habilitem essa função ao publicarem suas histórias).

9 Para um detalhamento acerca desses aspectos, veja a discussão apresentada por Azzari e Custódio (2013).

10 Percebe-se fanfic como um gênero discursivo a partir da teoria enunciativa bakhtiniana. Para Bakhtin, gêneros são enunciados que se caracterizam por sua forma, estilo, composição, tema e valoração, e estão social e historicamente situados em suas esferas de circulação (BAKHTIN, 1997).

11 Harry Potter é uma série de romances (tidos como fantásticos e/ou distópicos) escrita por J. K. Rowling, adaptada com grande sucesso mundial para o cinema. No presente artigo não há espaço para estabelecermos a discussão acerca do lugar da literatura fantasiosa e/ou distópica em relação ao cânone e nem é este nosso objetivo. No entanto, é importante notar que muitos dos textos que compóem a ciberliteratura, em especial os que constituem as ficçóes de fấs, são elaborados a partir da (re) leitura de textos distópicos, entre outras fontes de afiliação, conforme já mencionamos em nota anterior. Dentre esses textos, encontram-se também aqueles validados como cânone. As histórias motivadoras das ficções de fấs podem, assim, partir mesmo de seres e/ou objetos reais (um ator apreciado, por exemplo) ou de quaisquer outras formas de expressão artísticas (ficcionais ou náo), tais como letras de música ou um anime, que é o caso de Naruto, uma série japonesa escrita e ilustrada no gênero mangá por Masashi Kishimoto, mencionada também na fanfic ilustrada pela figura 2. 


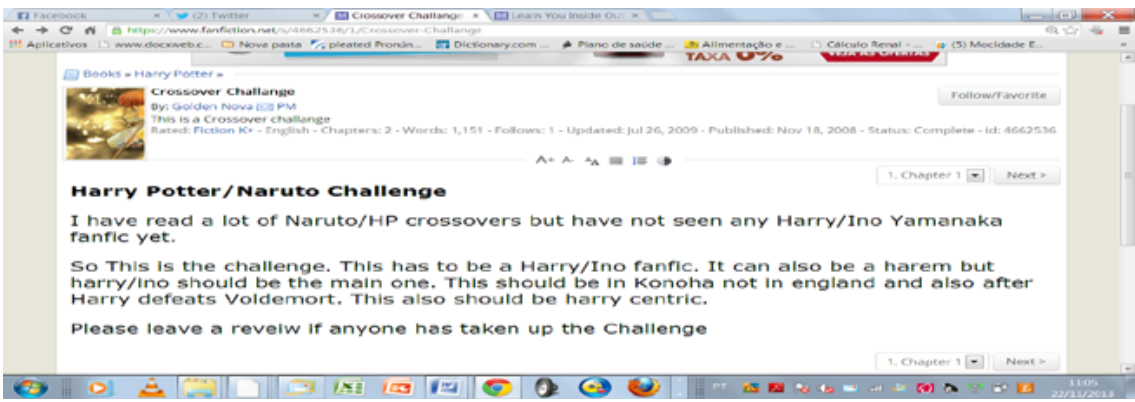

Figura 2 - Hibridismos na fanfic: estórias de fấs que cruzam gêneros, mídias e bases de afiliação diferentes. Disponível em: https://www.fanfiction.net/s/4662536/1/Crossover-Challange. Acesso em 22/11/2013.

Embora as fanfics independam do ambiente digital - há versôes impressas, tradição herdada das fanzines -, foi por intermédio da web 2.0 que esse gênero se popularizou e encontrou caminhos para expressar sua essência híbrida.

Talvez a maior página eletrônica para a publicação e leitura desse gênero (e também para a participação e afiliação às bases de fã̃) seja o endereço eletrônico < https://www.fanfiction.net/> (acesso em 22/11/2013). Nesse espaço é possível ler histórias de fâs escritas em mais de 20 línguas diferentes (incluindo latim!), muito embora a língua de comunicação predominante seja o inglês, língua da interface oficial do sítio na web e também a utilizada pela comunidade "fanfiqueira" em geral, para estabelecer as regras e regulamentaçôes que norteiam a escrita e a publicação das fanfics. Mas há também páginas como a Nyah!Fanfiction (disponível em: https://fanfiction.com.br/), hospedada em domínio (WWW) brasileiro, com interface em língua portuguesa do Brasil. Como é possível notar pela figura 3, o sítio Nyah!Fanfiction demonstra, já em sua página inicial, a preocupação em esclarecer a que se destina, enfatizando o papel de leitores e autores que se engajam nessa comunidade criativa. De maneira sistemática, a página oferece também dicas gramaticais, a fim de colaborar para a escrita dos textos de fấs (uma preocupação demonstrada também em outras comunidades fanfiqueiras, sugerindo, talvez, material para outras - futuras -, análises!). 


\section{Fanitiction}

Categorias Portuguess Ligados Betas Recentes Pesquisar Ajuda

As histórias postadas no site são criaçōes origina's ou fscç̄es criadas por fấs - fanfiction

- de animes, seriados, filmes, livros e muito mais. Este site fol criado com o intuito de

divulgar as séries originais, reunir seus fâs e proporcionar momentos de lazer através da

leitura, assim como incentivar as pessoas a trabalharem seu lado criativo escrevendo suas

próprias histórias.

Voce nào paga nada para ler ou postar no site, o uso é gratuitol

"HOUVERAM" MUITOS ACIDENTES

O verbo thaver", no sentido de existir, e invariavel; sendo assim $\rightarrow$ Houve muitos acidentes.

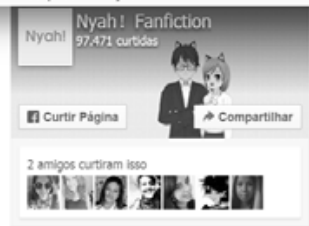

Melhores leitores da semana $\odot$

Figura 3 - Recorte da página inicial do sítio de publicaçôes de fanfics Nyah!Fanfiction. Disponível em: https://fanfiction.com.br/. Acesso em 19/01/2016.

Analisando o potencial papel da leitura e escrita da fanfic no desenvolvimento de letramentos de aprendizes de inglês como língua estrangeira, Black (2005) aponta as oportunidades oferecidas, em diferentes níveis, para o engajamento e a participação de jovens nas comunidades de fấs em um ambiente como o <fanfiction.net $>$. Ao filiar-se à comunidade, o participante inicialmente cria sua própria página em que estabelece sua identidade de acordo com suas preferências (musicais, de filmes, artistas, animês, quadrinhos, cânone, entre outras). É em meio a esse burburinho criativo, mediado por mixes e remixes de textos (frequentemente multimodais e multimidiáticos), que se assiste ao (re)surgimento da discussáo sobre os papéis de autor e leitor, mediante as tipificaçóes desses novos textos.

Além de ler, escrever e postar histórias, os membros dessas comunidades podem também comentar as publicaçóes (capítulo a capítulo), dialogar com os autores, ingressar em fóruns de discussão com outros leitores ou ainda habilitar-se como revisores (chamados de "beta-leitores"). Para Black (2005, p. 2), a participação nessas comunidades desperta não somente a afiliação a grupos de pessoas com apreciaçóes afins, mas, também, uma afiliação à língua em que são construídos os textos publicados em ambiente síncrono.

Para Jenkins et al (2006, p. 3) fanfics são exemplo de uma das "expressóes" que compóem as formas da cultura participativa, que é definida como aquela em que há:

1. barreiras relativamente pequenas à expressão artística e ao engajamento cívico;

2. um grande apoio à criação e ao compartilhamento das produçôes criadas com os demais; 
3. algum tipo de monitoria, de maneira que o integrante mais experiente transmita seus conhecimentos aos principiantes;

4. crença, por parte dos integrantes, de que suas contribuições sejam relevantes;

5. um certo grau de conexão social entre os participantes (que ao menos se importam com o que os outros pensam sobre suas criaçôes). (JENKINS et al, 2006, p. 7, nossa tradução).

Segundo ainda esses autores, desenvolver as capacidades necessárias para atuar na cultura participativa é parte integrante na formação curricular do jovem contemporâneo.

A hipertextualidade operacionalizada pela digitalização (SANTAELLA, 2011, p. 301) é uma das propiciaçóes ${ }^{12}$ de que fazem uso os autores de fanfics quando, não raro, decidem integrar diferentes modalidades (imagens móveis e estáticas e/ou áudio, por exemplo) e mídias (fóruns, redes sociais, blogs, Tumblr) ao texto. Nesse sentido, é comum observar-se, por exemplo, leitores revertendo-se para o papel de autor ao elaborar banners para as histórias de seus autores favoritos, como ilustra a figura 4. A autora (que assina com o pseudônimo Tongue-Twied), nas notas iniciais (texto em negrito), diz: "Eu tenho amigas talentosas de verdade! Veja o banner para a história feito para mim colaborativamente por 17ForeverLisa e CreationsJules [outras duas autoras/leitoras da comunidade]. O link está na minha página de perfil. Olhe atentamente nas folhas!” (nossa tradução).

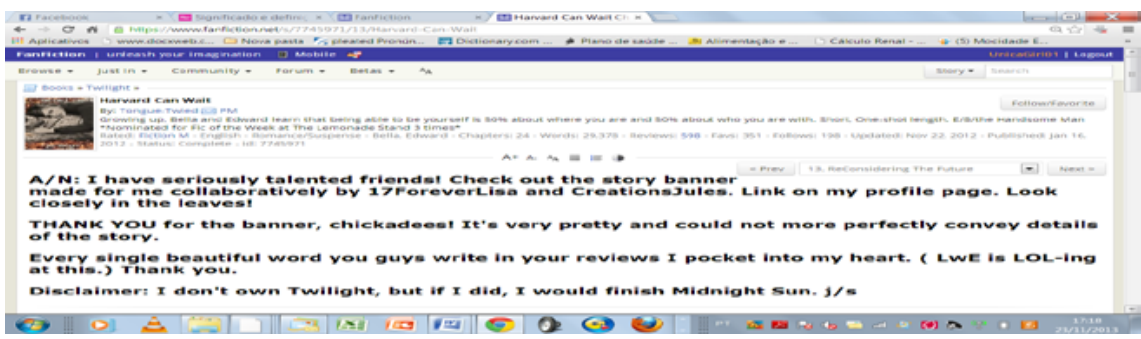

Figura 4 - A multimodalidade e a autoria na fanfic. Um exemplo de menção de produção de banner. Fonte: https://www.fanfiction.net/s/7745971/13/Harvard-Can-Wait. Acesso: 23/11/2013.

12 Propiciaçôes ou propiciamentos (como prefere PAIVA, 2009) é um termo cunhado, originalmente em inglês ("affordances"), no âmbito de estudos da ecologia e que foi posteriormente movido para o campo das pesquisas sobre segunda língua por Van Lier. Para esse autor, propiciaçáo é "aquilo que está disponível para a utilização da pessoa" (2004, p. 91, apud PAIVA, 2009). 
Já a figura $5^{13}$ mostra a página de perfil da autora Tongue-Twied (criada no sítio <fanfiction.net>) e os diversos hiperlinks que remetem a banners elaborados por lautores $^{14}$ (leitores-autores), entre outras páginas da web.

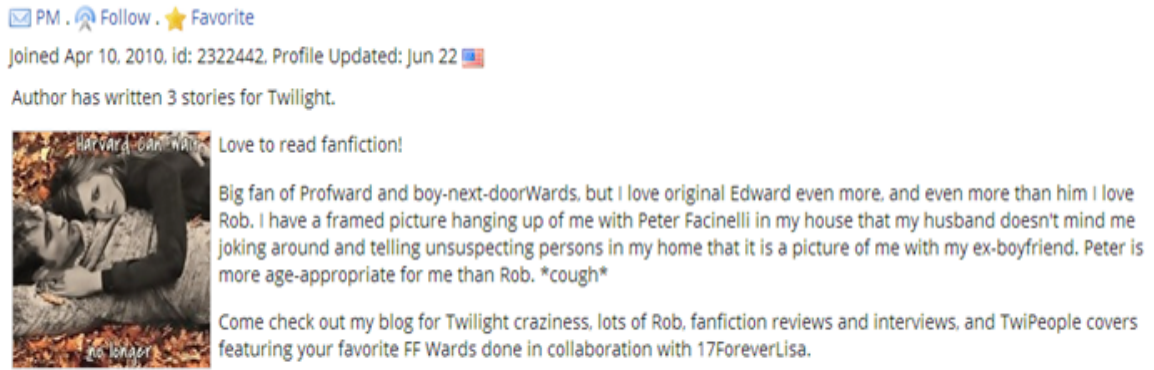

www.tonguetwied.blogspot.com

Lovely Pics, Banners, Story tributes my friends were inspired to make

Story Banners made by creationsjules and 17 foreverlisa

Banner 1

http://i995.photobucket.com/albums/af73/TongueTwied/HarvardCanWait_Banner.png

Banner 2

http://ig95,photobucket.com/albums/af73/TongueTwied/Harvard_can_wait.png

From BellaTesoro http://i995.photobucket.com/albums/af73/TongueTwied/MarryMe-1.png

Figura 5 - Página de perfil de autora de fanfic e seus hiperlinks. Disponível em: https:// www.fanfiction.net/u/2322442/Tongue-Twied. Acesso em 23/11/2013.

13 Recorte da página do perfil de Tongue-Twied, a figura informa que a autora faz parte da comunidade desde 2010 e que, até o momento da (então) última atualização de seu perfil (22/06/2013), havia escrito (e publicado no sítio) 3 histórias dentro da base de fãs de Crepúsculo. A autora informa "amar ler fanfiction"; fala sobre que tipo de variação ficcional de fấ a partir dos personagens da saga prefere escrever/ler; e associa o personagem principal, Edward, ao ator que o interpretou no cinema (muitos desses lautores (leitores-autores) ingressaram na comunidade fanfic após assistirem aos filmes que adaptaram os romances para o cinema). Entre outros dados, a autora informa links para suas outras páginas em sítios da web, como blogs e outras comunidades que abrigam redes sociais para a publicação/circulação de textos escritos e/ou imagéticos.

14 Rojo (2013, p. 20) sugere o termo "lautor" ao discutir o papel que assumem o autor e leitor nas (novas) construções, criações e produções possibilitadas pelas TDICs, sob a ótica da abordagem dos multiletramentos. 
A figura 6 apresenta o banner mencionado na figura 4, criado à guisa de pôster ilustrativo para a história "Harvard can wait" ("Harvard pode esperar"), centrada na base de fấs da saga Crepúsculo.

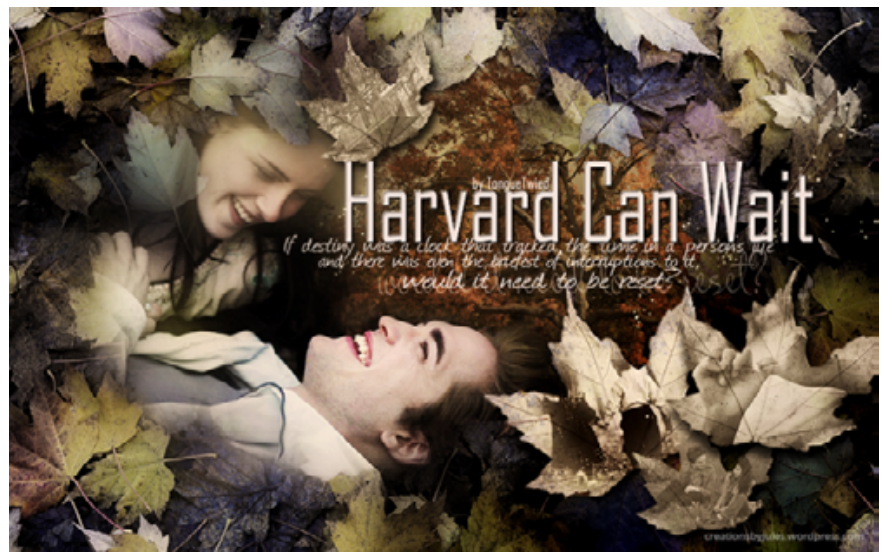

Figura 6 - Banner elaborado colaborativamente por lautores para uma fanfic.

Fonte: http://i995.photobucket.com/albums/af73/TongueTwied/HarvardCanWait_ Banner.png. Acesso em 23/11/2013.

Prática corrente nas comunidades fanfiqueiras, os banners criados para as histórias parecem preencher a necessidade desses lautores de associar imagens aos textos, ilustrando-os. Além das imagens estáticas, é comum também a criação de vídeos e a sugestão de listas de músicas que compóem, por variadas vezes, a "trilha sonora" dos capítulos publicados. Apropriando-se da hipertextualidade, esses diversos modos e mídias para a construção de sentidos são associados ao texto verbal, num trabalho colaborativo entre leitor e autor, cujas fronteiras acabam borradas, misturando-se no papel lautor.

Tanto as histórias desses fẫ quanto as ilustrações a elas associadas são releituras, remixes, ou redesigns (como sugerem COPE; KALANTZIS, 2009, p. 12) de outras histórias, imagens, criaçóes que despertaram nessas comunidades de fấs o desejo de ler e escrever, de criar recriando. Personagens, enredos, cenários, fotos, imagens estáticas e em movimento são reapropriadas, revisitadas, numa releitura que provoca um repensar das fronteiras e forças que legitimam textos e os privilegiam em contexto escolar para a formação do aluno-leitor. 
Para Jenkins (2006, p. 2), as histórias de fâs surgem "tanto a partir do fascínio quanto da frustração" que esses lautores sentem em relação às obras inspiradoras. São esses sentimentos que geram a empatia fã/texto e causam o engajamento necessário para que alguém decida dedicar-se à prática de escrever ficçóes amadoramente e sem fins lucrativos. Nesse processo, formam-se leitores à moda crítica e que se tornam, igualmente, criativos.

Nessa direção, Jenkins (2012) retoma a discussão estabelecida pela poetisa Sheenag Pugh (2006) para dissertar acerca das razóes que motivam a escrita do gênero ficção de fã. Em seus comentários, Jenkins (2012, p. 14) destaca como a discussão que Pugh estabelece em seu livro The Democratic Art aponta para o surgimento de escritores profissionais que têm lançado novos olhares ao cânone, por exemplo, a fim de redirecionar e expandir algumas narrativas. Apoiando-se em Bacon Smith (1992) Jenkins declara que

fấs estão buscando potencial não aproveitado na história que poderia ter oferecido uma plataforma inicial para suas próprias atividades criativas. Podemos identificar pelo menos cinco elementos básicos que inspiram intervençóes de fấs. Aprendendo a ler como um fấ normalmente envolve aprender a encontrar tais brechas (JENKINS, 2012, p. 16).

Mais adiante, no mesmo artigo, Jenkins (2012) propóe uma leitura do clássico Moby Dick, de Herman Melville, através das lentes de um fă, como tipificado nas comunidades de leitura e escrita de fanfics. O autor aponta alguns dos elementos em "potencial não aproveitado na história" utilizando-os por categorias de análise - tipificadas pelo modo como os leitores-fâs interagiriam com os textos literários, não somente à maneira de leitura crítica, mas, igualmente, criativamente. Entre essas categorias ou "brechas", estariam: "sementes; buracos; contradiçóes, silêncios e potenciais" detectados pelo olhar desses atentos leitores (JENKINS, 2012, p. 16-19).

O leitor desenhado por Jenkins assume, dessa forma, o papel de crítico literário, cujos critérios para avaliação da obra são talhados à maneira hermenêutica, interativa, colaborativa (quando partilhada em uma comunidade de fấs a que se afilie e de que se faça membro), e que se apropria de conhecimentos diversos, tais quais: de língua/linguagem; de mundo; do cânone e/ou do 
fantástico literário; de textos multimodais e multimidiáticos e das interlocuções que estabelece em sua base de fã para elaborar sua leitura e, eventualmente, aventurar-se na escrita ficcional criativa.

Ao final de sua leitura-análise de Moby Dick pelas lentes do leitor-fã, Jenkins (2012) lança como provocação um possível deslocamento desse paradigma que orienta lautores fora da esfera escolar, sugerindo que "professores podem descobrir que muitos estudantes respondem bem ao receberem pedidos de analisar Moby Dick e outros textos literários através dessa lente" (2012, p. 19). Dessa forma, Jenkins não professa que se estimule, em esfera escolar, a leitura das ficçôes de fấs, mas sim que as tomemos como base para que, analisando-se o funcionamento dessa intricada rede de leitura/escrita, colaboração, produção e circulação textual, seja possível trazer um novo olhar para a maneira como se pensa a formação (na educação regular) de leitores (e, por que também não dizer, de escritores?).

Percebendo-se a reconfiguração dos textos de ficção (que, assumindo pluralismos estéticos, estilísticos, de linguagem e também de vozes, tornam-se fluídos, inacabados), torna-se possível, através dos recursos dos ambientes digitais síncronos, a igual ressignificação da literatura e do leitor. É então, diante desse quadro, que se torna possível observar rupturas a partir das quais se torna concreto o repensar da formação de leitores contemporâneos também em ambiente escolar.

\section{Considerações finais}

Considerando o descompasso entre as escolhas feitas pelas instituiçóes que determinam o cânone e as do público, abordado no início dessa breve reflexão, a escola, como agência privilegiada de letramentos, tem como papel ser veiculadora náo apenas do conjunto de autores representativos de uma cultura nacional, mas também propagar os textos representativos dos demais sistemas que compóem o território literário, permitindo ao aluno perceber a literatura como um sistema múltiplo (um polissistema) que abriga em seu interior diferentes sistemas com os quais o cânone dialoga. Para tanto, é preciso romper alguns paradigmas, tais como aqueles que anunciam quais textos (e quais fazeres) legitimam a literatura, bem como os próprios processos de escrita e leitura - e, por conseguinte, a formação de leitores. 
Os currículos escolares ainda são construídos à maneira verticalizada e, muitas vezes, representam discursos excludentes que determinam visóes monolíticas de língua/linguagem e culturas, em que dados textos são privilegiados, em ciclos alternados, em detrimento de outros que igualmente permeiam e constituem os contextos e experiência de leitura e escrita de jovens alunos, além dos limites dos muros das escolas. Uma das tarefas na formação do aluno-leitor na atualidade, portanto, parece ser a de aproximar esses universos, pensando currículos à maneira mais horizontal e, por conseguinte, democratizada.

Ao aproximar-se das comunidades síncronas em que textos são produzidos, compartilhados, comentados, lidos e relidos, no processo democratizante e constituinte da ciberliteratura e, mais especificamente, da cultura de fâs, o professor pode encontrar não somente fonte para questionar conceitos (tais como os de literatura e cânone), como também brechas para reavaliar os caminhos que traça para a formação de leitores nos espaços escolarizados.

Como afirma Lemke (2010), o paradigma interativo circula, hoje, na escola e dá àqueles que têm acesso aos gêneros que, a exemplo das fanfics, apoiam-se nas tecnologias síncronas, o poder de escolher o que, quando e como ler (e aprender). Ao formador de alunos-leitores resta, entáo, buscar meios para construir as pontes que aproximem esses diferentes tempos-espaços de produçáo e leitura de textos ficcionais, sejam eles integrantes ou não do cânone.

É por conjugar cultura popular e literatura canônica que, segundo Viires (2005), gêneros como a ficção de fấs têm sido relegados à periferia literária. Como também aponta o autor, é preciso acatar que, na atualidade, a rede mundial de computadores funciona como uma central para a publicaçáo e a divulgaçáo da obra de autoria amadora, expandindo a definição de ciberliteratura para portais abertos (e gratuitos!) de escrita e leitura colaborativa, redesenhando espaços e conceitos de autoria, leitura e literatura, à maneira contextualizada por pertencimentos e filiaçóes.

Assim como sugere Jenkins (2012), talvez um caminho para formação de alunos-leitores (mais) críticos e criativos não esteja exatamente (e exclusivamente) a entrada dos textos de făs nas práticas e rotinas escolares, mas sim, as possibilidades que esse gênero oferece para que se repense o papel da escrita e da leitura nos dias correntes. 
Ademais, as práticas de leitura e escrita promovidas nas comunidades de fấs ilustram de que forma centro e periferia do cânone convivem, permitindo tanto a professor quanto aluno, no ambiente escolar, reflexão sobre os critérios e juízos de valor considerados quando se trata do objeto literário, seja ele uma obra considerada canônica (caso de Moby Dick, aqui citado); seja uma obra dita de mercado (Harry Potter e Crepúsculo).

A formação do leitor, portanto, deve considerar essa teia complexa que a atualidade impóe como realidade tanto ao professor de literatura quanto aos estudantes. Nesse cenário, o cânone parece se revigorar, em suas infindas recriações, reelaboraçóes, dentro do jogo da comunidade fanfiqueira, espaço democrático, mas não sem regras, da liberdade criativa. E não apenas como recriação do cânone, mas como apropriação e transgressão dos critérios valorativos do que é ou não literatura, do que vale ou não quando se trata do objeto literário, dos juízos de valor a serem consideradas na análise da obra, exercício fundamental para a formação do leitor literário.

Talvez, ainda, uma das brechas apresentadas por esse caminho advenha exatamente das respostas que possa oferecer ao professor atento às culturas que permeiam o cotidiano de jovens alunos e que se pergunte: por que ainda é tão difícil engajar alunos na escrita e na leitura de textos em esfera escolar quando, movidos por afiliaçóes, hipertextos e multimodalidades, esses mesmos jovens se propóem a ler (e a escrever) de forma tão abundante e voluntária? Que liçôes sobre ler e formar leitores se pode abstrair a partir de um olhar analítico para a produçáo da ficção de fâs? Ficam aqui (algumas) provocações para que continuem os diálogos.

\section{Referências}

AZZARI, E.F.; CUSTÓDIO, M.A., Fanfics, Google Docs... a produção textual colaborativa. In: ROJO, R.H.R. (org.).Escol@conect@d@: os multiletramentos e as TICs. São Paulo: Parábola Editorial, 2013, p. 73-92.

BAKHTIN, M. Os gêneros do discurso. In: Estética da criação verbal. Trad. Maria Ermantina Galvão G. Pereira. São Paulo: Martins Fontes, 1997, 2ª ed., p. 277-289.

BLACK, R. W. Access and affiliation: the literacy and composition practices of English-Language learners in an online fanfiction community. Journal of Adolescent \& Adult Literacy, v. 49(2): 118-128, 2005, 10.1598/JAAL.49.2.4. Disponível em: http://onlinelibrary.wiley.com/doi/10.1598/JAAL.49.2.4/abstract, 08/12/2011. 
Digital design: English Language learners and reader reviews in online fiction. In: LANKSHEAR, C.; KNOBEL, M. (Orgs.). A new literacies sampler. New York: Peter Lang, 2007, p. 115-136.

BOURDIEU, P. As regras da arte. São Paulo: Companhia das Letras. 1996.

CASANOVA, P. A república mundial das letras. São Paulo: Estação Liberdade. 2002.

COMPAGNON, A. O demônio da teoria. Belo Horizonte: Ed. UFMG. 2001. COPE, B.; KALANTZIS, M. Multiliteracies: new literacies, new learning. Pedagogies: An International Journal, v. 4(3): 164-195, 2009. Disponível em: http://newlearningonline.com/kalantzisandcope/research-and-writing/, 28/07/2011.

EVEN-ZOHAR, I. Polysystem Studies. 1990. Disponível em: www.tau. ac.il/-itamarez/works/books/index.html, 10/08/2007.

JENKINS, H. Textual poachers: Television, fans, and participatory culture. New York, NY: Routledge. 1992.

. Fan fiction as critical commentary. 27 set 2006. Disponível em< henryjenkins.org/2006/09/fan_fiction_as_critical_commen.html>, 25/11/2013.

. Lendo criticamente e lendo criativamente. In: Revista Matrizes, ECA/ USP, São Paulo. V. 6, nº. 1-2, 2012.

JENKINS, H. et al, Confronting the challenges of participatory culture: media education for the 21st Century, MacArthur Foundation, 2006. Disponível em: < http://digitallearning.macfound.org/site/c.enJLKQNlFiG/b.2108773/ apps/nl/content2.asp?content_id=\%7BCD911571-0240-4714-A93B1D0C07C7B6C1\%7D\&notoc=1>, 22/11/2013.

LANKSHEAR, C.; KNOBEL, M. (orgs.) Digital literacies - Concepts, policies and practices. New York, Peter Lang, 2008.

LEMKE, J. L. Letramento metamidiático: transformando significados e mídias. Revista Trabalhos em Linguistica Aplicada, 49(2): 455-479. Trad. Carla Dornelles. Campinas, SP: IEL/UNICAMP, 2010.

PAIVA, V. L. M. de O. Propiciamento (affordance) e autonomia na aprendizagem de língua inglesa. In: LIMA, Diógenes Cândido. Aprendizagem de lingua inglesa: histórias refletidas. Vitória da Conquista: Ediçóes UESB, 2010.

ROJO, R. Gêneros discursivos do Círculo de Bakhtin e os multiletramentos. In: ROJO, R. H. R. (org.).Escol@conect@d@: os multiletramentose as TICs. São Paulo: Parábola Editorial, 2013, p. 13-36. 
SANTAELLA, L. Linguagens líquidas na era da mobilidade. 2. ed. São Paulo: Paulus, 2011.

VIIRES, P. Literature and Cyberspace. Folklore, 29: 153-174, 2005. Disponível em: http://www.folklore.ee/folklore/vol29/cyberlit.pdf, 03/12/2011.

\section{LITERATURE, CIBERLITERATURE AND THE INSTRUCTION OF A STUDENT-READER: DIALOGUES WITH CANON AND FAN FICTION}

ABSTRACT: Contemporary texts have been re-signified by the development of online technology so that such texts favor collaboration and interaction between authors and readers thus reconfiguring their roles. The current paper aims at revisiting the place of reading and the reader position by discussing the place occupied by the canon and the fanon (neologism to fan texts) in scholar literacies at the present days.

KEY-WORDS: Literacies; Literature; Digital technologies.

Recebido em: 20/10/2015

Aprovado em: 23/02/2016 